DOE/ER/14056-14

\title{
DIRECT PROBING OF CHROMATOGRAPHY COLUMNS BY LASER-INDUCED FLUORESCENCE
}

Technical Progress Report

September 1, 1989 - February 28, 1993

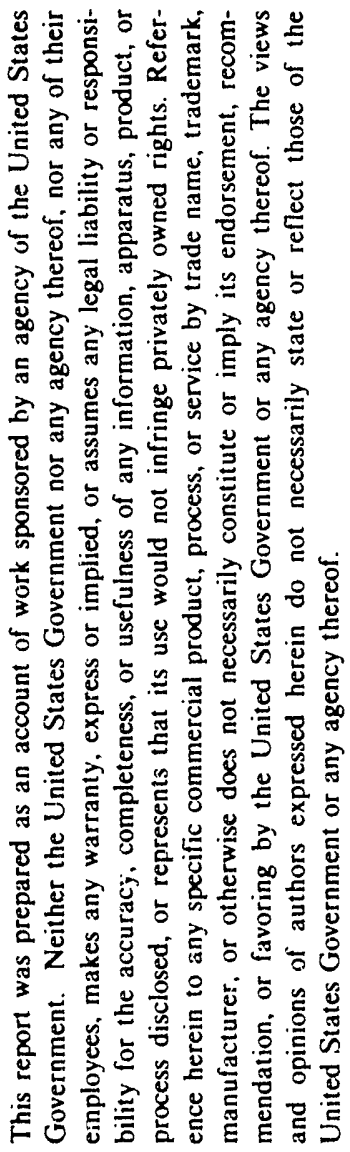

Victoria L. McGuffin

Department of Chemistry

Michigan State University

East Lansing, Michigan 48824

December 7, 1992

Prepared for

THE U.S. DEPARTMENT OF ENERGY

CONTRACT NO. DE-FG02-89ER14056 


\title{
DIRECT PROBING OF CHROMATOGRAPHY COLUMNS BY LASER-INDUCED FLUORESCENCE
}

\author{
Final Technical Progress Report \\ September 1, 1989 - February 28, 1993
}

\section{TABLE OF CONTENTS}

$\begin{array}{ll}\text { ABSTRACT } & 1\end{array}$

INTRODUCTION 2

SCIENTIFIC OBJECTIVES OF THE RESEARCH PROJECT 2

PROGRESS REPORT 3

I. EXPERIMENTAL SYSTEM 3

On-Column Laser-Induced Fluorescence Detection System Stereomicroscope

II. SOLUTE RETENTION AND DISPERSION IN TRANSITION REGIONS 6 Injection Nonequilibrium

Elution Nonequilibrium

III. SOLUTE RETENTION ALONG THE CHROMATOGRAPHIC COLUMN Solute Retention at Varying Temperature and Constant Pressure Solute Retention at Varying Pressure and Constant Temperature Combined Effect of Temperature and Pressure

Thermodynamic Model of Solute Retention

IV. SOLUTE DISPERSION ALONG THE CHROMATOGRAPHIC COLUMN

V. RELATED STUDIES

Determination of Physiologically Important Fatty Acids

Photophysical Properties of Pyrene as a Polarity Probe

Fluorescence Quenching of Polynuclear Aromatic Hydrocarbons

SUMMARY

3822

REFERENCES 22

PUBLICATIONS AND REPORTS OF THE RESEARCH PROJECT 24

PERSONNEL OF THE RESEARCH PROJECT 2.5

APPENDICES 


\begin{abstract}
This report summarizes the progress and accomplishments of this research project from September 1, 1989 to February 28, 1993. During this period, we have accomplished all of the primary scientific objectives of the research propcsal: 1) constructed and evaluated a laser-induced fluorescence detection system that allows direct examination of the chromatographic column, 2) examined nonequilibrium processes that occur upon solute injection and elution, 3) examined solute retention in liquid chromatography as a function of temperature and pressure, 4) examined solute zone dispersion in liquid chromatography as a function of temperature and pressure, and 5) developed appropriate theoretical models to describe these phenomena. In each of these studies, substantial knowledge has been gained of the fundamental processes that are responsible for chromatographic separations.

Ir. addition to these primary research objectives, we have made significant progress in three related areas: 1) examined pyrene as a fluorescent polarity probe in supercritical fluids and liquids as a function of temperature and pressure, 2) developed methods for the class-selective identification of polynuclear aromatic hydrocarbons in coal-derived fluids by microcolumn liquid chromatography with fluorescence quenching detection, and 3) developed methods for the determination of saturated and unsaturated (including omega-3) fatty acids in fish oil extracts by microcolumn liquid chromatography with laser-induced fluorescence detection. In these studies, the advanced separation and detection techniques developed in our laboratory are applied to practical problems of environmental and biomedical significance.
\end{abstract}

\title{
NOTICE
}

This report was prepared as an account of work sponsored by the United States Government. Neither the United States nor the Department of Energy, nor any of their employees, nor any of their contractors, subcontractors, or their employees, makes any warranty, express or implied, or assumes any legal liability or responsibility for the accuracy, completeness, or usefulness of any information, apparatus, product, or process disclosed or represents that its use would not infringe privately-owned rights. 


\section{INTRODUCTION}

The correlation between theory and experiment has been, and still remains today, one of the most fundamentally important and challenging problems in separation science. It may be difficult to understand, at first glance, why this problem has not yet been completely solved by the many active and knowledgeable researchers in the field. After all, solute retention is simply an attempt to understand and to control thermodynamics and kinetics, while solute zone dispersion is an attempt to understand and control hydrodynamics. The fields of thermodynamics, kinetics, and hydrodynamics have been studied in great depth and breadth by chemists and chemical engineers for many years. So why is there a difficulty in correlating theory and experiment in chromatography? Simply stated, the problem is as follows: The thermodynamic and kinetic processes that cause solute retention are concentration dependent and, therefore, are different in static and dynamic systems. The most detailed studies of thermodynamics and kinetics have bean performed in static systems. Similarly, the hydrodynamic processes that are responsible for solute zone dispersion are different in retentive and nonretentive systems, where most of our present knowledge resides. The combined effect of retention and dispersion processes is only fully understood for relatively simple chromatographic systems, such as gas chromatography performed in an open-tubular capillary column with a thin, uniform film of a nonpolar stationary phase. The combined effect is poorly understood for the complex physical and chemical systems that arise in liquid chromatography, which include packed beds, mobile and stationary phases that are heterogeneous, strong chemical interactions that result in nonideal and nonlinear behavior, etc.

A further complication to this problem arises because, in all previous investigations, experimental measurements have been performed by using a detector situated at the end of the chromatographic column. These measurements reflect, at best, a spatial and temporal average of solute retention and dispersion along the entire column. More typically, these measurements also include contributions that arise outside of the column proper. The goal of this research project was to develop a detection system that allows the direct interrogation of the chromatographic column. This system permits the measurement of solute retention and dispersion in small, isolated regions of the column in which the experimental conditions are well controlled and extra-column contributions are eliminated. Under these conditions, the experimental data are sufficiently accurate that they may be compared with the most rigorous theoretical models.

\section{SCIENTIFIC OBJECTIVES OF THE RESEARCH PROJECT}

The scientific objectives of the research project were originally stated as follows:

1. To develop a laser-induced fluorescence system capable of simultaneous detection at multiple points along a chromatographic column.

2. To develop and validaie the computer software necessary to acquire and display data and to perform calculations.

3. To utilize this system to examine solute zone retention and dispersion in regions of spatial transition, such as injection and elution processes. 
4. To utilize this system to examine the hydrodynamic dispersion of solute zones in uniformly packed beds as a function of the colum.1-to-particle diameter ratio.

5. To utilize this system to examine solute retention as a function of mobilephase composition under both isocratic and gradient conditions.

6. To correlate the retention and dispersion measurements derived from each of these studies with appropriate theoretical models.

During the course of these studies, we observed several interesting and previously unreported phenomena concerning the thermodynamic behavior of octadecylsilica, the most common stationary phase for liquid chromatography. Because of the significance of these results and their direct consequences on the remainder of our proposed studies, we have revised the goals of the research plan. The scientific objectives stated above have been modified as follows:

4. To utilize this system to examine solute retention as a function of temperature and pressure. To characterize the thermodynamic behavior of the octadecylsilica stationary phase near the phase transition.

5. To utilize this system to examine solute zone dispersion as a function of linear velocity in uniformly packed beds. To elucidate the mathematical form of the retention-dependent contributions to dispersion, corrected for the effects of temperature and pressure.

6. To correlate the retention and dispersion measurements derived from each of these studies with appropriate theoretical models.

Our progress and accomplishments in these and related areas of research supported by the Department of Energy, Office of Basic Energy Sciences, will be briefly summarized in this report.

\section{PROGRESS REPORT}

\section{EXPERIMENTAL SYSTEM}

\section{ON-COLUMN LASER-INDUCED FLUORESCENCE DETECTION SYSTEM}

The experimental system, which was designed and constructed in our laboratory, is shown schematically in Figure 1. The individual components of this system are described in detail below.

Chromatographic System. The mobile phase is delivered by a single-piston reciprocating pump, operated in the constant-pressure mode. The sample is introduced by means of a 1.0- $\mu \mathrm{L}$ injection valve and is subsequently split between the microcolumn and a capillary, resulting in a nominal injection volume of $10 \mathrm{~nL}$ and a nominal flowrate of $1 \mu \mathrm{L} / \mathrm{min}$. 


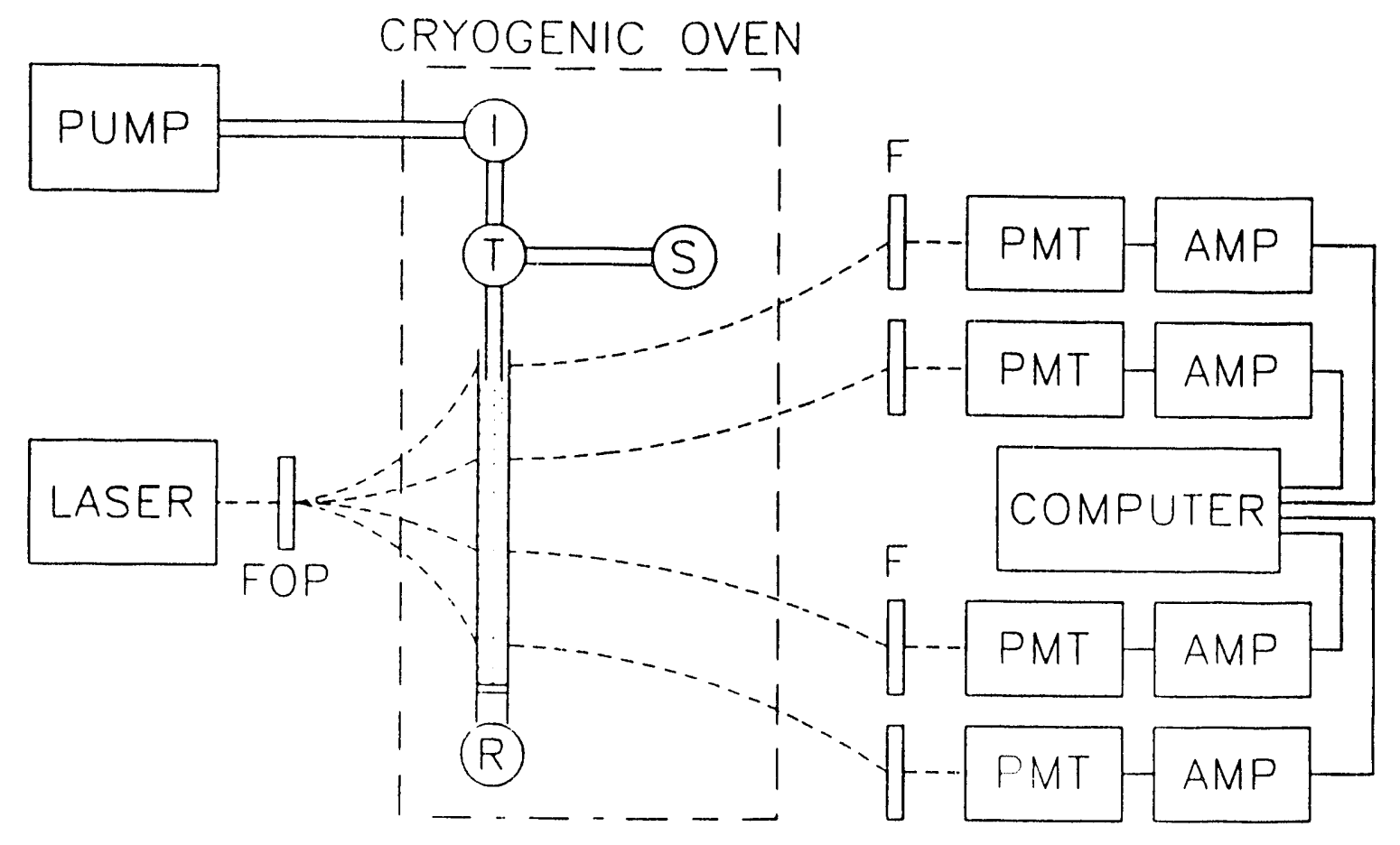

FIGURE 1: Schematic diagram of the experimental system. $I=$ injection valve, $T=$ splitting tee, $S=$ splitting capillary, $R=$ restricting capillary, FOP $=$ fiberoptic positioner, $F=$ filter, $\mathrm{PMT}=$ photomultiplier tube, $\mathrm{AMP}=$ amplifier .

The microcolumns are fabricated from 200- $\mu \mathrm{m}$ i.d. fused-silica capillary tubing that is terminated with a quartz wool frit. Prior to packing, the polyimide coating is removed from the capillary at selected positions to facilitate on-column detection. The packing material (Varian MicroPak SP-18) is a 3- $\mu \mathrm{m}$ spherical silica with a surface area of 200 $\mathrm{m}^{2} / \mathrm{g}$ that has been reacted with a monofunctional octadecylsilane at a bonding density of $3.5 \pm 0.1 \mu \mathrm{mol} / \mathrm{m}^{2}$ and subsequently capped with trimethylchlorosilane (1). A slurry of this octadecylsilica packing material in methanol is introduced onto the capillary under moderate pressure (5000 psi). A typical column prepared in this manner has a plate height $(H)$ of $9.5 \mu \mathrm{m}$, a total porosity $\left(\varepsilon_{\mathrm{T}}\right)$ of 0.58 , and a flow resistance parameter $\left(\phi^{\prime}\right)$ of 550 under standard test conditions (2). These physical properties remain relatively constant along the length of the column (3).

For the injection studies, a short length of open-tubular fused-silica capillary $(50-\mu \mathrm{m}$ i.d.) is utilized to connect the injector to the microcolumn. For the elution studies, a similar capillary is attached at the column outlet. These arrangements facilitate the placement of detectors within the transition region to the packed bed at the column irilet and outlet.

For the thermodynamic studies, an open-tubular capillary $(20-\mu \mathrm{m}$ i.d. $)$ is attached at the column outlet to serve as a restrictor. The lengths of the restricting and splitting capillaries are decreased proportionally, so that the mobile-phase linear velocity and split ratio remain constant while the inlet pressure is reduced from 4950 to 1500 psi. The column, splitter, and restrictor are maintained at constant temperature $\left( \pm 0.1^{\circ} \mathrm{C}\right)$ between 10 and $90^{\circ} \mathrm{C}$ in a cryogenically cooled oven. 
Detection System. Laser-induced fluorescence is utilized to probe solute zones at two to six positions along the microcolumn (3-10). A continuous-wave He-Cd laser ( $325 \mathrm{~nm}$, $10 \mathrm{~mW}$ ) is utilized as the excitation source and is transmitted to the column via UVgrade optical fibers. The fluorescence emission is collected in a right-angle, coplanar geometry by using optical fibers, isolated by appropriate interference filters or a monochromator, and detected by a photomultiplier tube. The resulting photocurrent is amplified and converted to the digital domain. Data acquisition, storage, and display are performed simultaneously at each detector by using computer programs developed in our laboratory with the Forth-based programming language, Asyst. Finally, the solute zone profiles are characterized by means of statistical moments to yield the most accurate measure of retention and dispersion processes (11).

Reagents. Saturated fatty acid standards ranging from $n-C_{10}$ to $n-C_{24}$ are derivatized with 4-bromomethyl-7-methoxycoumarin as described previously (12). Individual fatty acid derivatives are then isolated and purified using a conventional-scale octadecylsilica column (Applied Biosystems ODS-224) with methanol as the mobile phase. The resulting fractions are evaporated with dry nitrogen and are redissolved in methanol at a final concentration of $5 \times 10^{-4} \mathrm{M}$.

This homologous series of solutes is uniquely well suited for this application because it fulfills the requirement for fluorescence detection and chromatographic retention independently. The fluo:escent coumarin moiety allows for sensitive detection (10-10 M) with a broad linear dynamic range (108) (12). However, it does not appear to contribute to solute retention because it is soluble only in the methanol mobile phase but not in the octadecylsilica stationary phase (6). In a complementary fashion, the hydrocarbon chain is not spectroscopically active but serves to control solute retention in a theoretically predictable manner (6). The interaction of the alkyl moiety with the octadecylsilica stationary phase arises primarily from van der Waal (induced dipole) forces, the most universal of molecular interactions, making the results of general interest and applicability.

\section{STEREOMICROSCOPE}

In order to permit visual inspection of the chromatographic columns, a stereo-compound microscope system has been assembled. This microscope allows magnification in the range of 10 to $1200 \mathrm{X}$ and, with accurate calibration, permits size measurements in the range of 1 to $500 \mu \mathrm{m}$. Thus, accurate determination of the particle size (typically $3-10$ $\mu \mathrm{m}$ ) and column diameter (typically 50-320 $\mu \mathrm{m}$ i.d.) is possible simultaneously. This microscope is routinely used in our laboratory to assess the packing structure along chromatographic columns prior to their use for retention and dispersion measurements. 


\section{SOLUTE RETENTION AND DISPERSION IN TRANSITION REGIONS}

After any rapid change in the physical or chemical environment, some time is necessary before equilibrium can be reestablished. In chromatographic applications, such nonequilibrium conditions exist to some extent continually as the solute zone travels along the column (13). However, a further departure from equilibrium occurs specifically on injection of a solute zone onto the chromatographic column and on elution of the zone from the column. The unique ability of the on-column fluorescence detectors to isolate specific regions of the column affords a direct view of both injection and elution processes that was not previously possible. A brief description of our research progress in each area follows.

\section{INJECTION NONEQUILIBRIUM}

In most theoretical models of chromatographic separations, the solute is initially presumed to be present on the column with a narrow rectangular profile, fully equilibrated between the mobile and stationary phases. In practice, however, the solute zone must pass from a nonretentive injection valve or open tube onto the retentive packed bed. This spatial discontinuity in the physical and chemical environment inherent in the injection process may influence both the retention and dispersion of the solute zone. Previous investigations of the injection process have been limited by the inability to probe solute zones directly in the inlet region of the column.

In this study, the solute zones are monitored in situ by positioning one detector along an open tube immediately prior to the packed bed and five detectors sequentially along the column at $5-\mathrm{cm}$ intervals. Upon injection of the model solutes, a decrease in length variance and a concomitant increase in concentration are measured as a function of the solute capacity factor. This decrease in variance may be predicted theoretically using a simple steady-state model of the injection process developed in our laboratory (5):

$$
\left(\sigma_{L}{ }^{2}\right)_{O N}=\left(\sigma_{L}{ }^{2}\right)_{O F F} \frac{r^{4} \text { OFF }}{r^{4} O N} \frac{1}{\varepsilon_{T}{ }^{2}} \frac{1}{\left(1+k_{I N J}\right)^{2}}
$$

where $\left(\sigma_{L}{ }^{2}\right)_{O F F}$ and $\left(\sigma_{L}^{2}\right)_{O N}$ are the length variances measured immediately prior to and directly on the packed bed, respectively. In this equation, the physical or structural transition within this region is reflected in the terms that contain the radius $(r)$ and total porosity $\left(\varepsilon_{T}\right)$, which are the same for all solutes; the transition in chemical environment is reflected in the term involving the capacity factor $(k)$, which is clearly solute dependent. Excellent agreement is observed between experimental measurements and theoretical predictions based on this model, as shown in Figure 2.

Equation [1] suggests that the solute zone variance is influenced by the composition of the injection solvent; a solvent that is weaker than the mobile phase $\left(k_{I_{N J}}>k_{M P}\right)$ will cause zone compression, whereas one that is stronger $\left(k_{I_{N J}}<k_{M P}\right)$ will cause expansion. This hypothesis has been tested by using 90 and $95 \%$ methanol-water mixtures (weaker) as well as 90 and $95 \%$ methanol-acetone mixtures (stronger) as injection solvents with a pure methanol mobile phase. Although the overall retention does not change because the solute zone is rapidly separated from the injection solvent, the zone variance is altered dramatically with injection solvent composition and the experimental measurements agree well with theoretical predictions using Equation [1] (5). This effect may be exploited to preconcentrate the solute at the column inlet and to reduce extracolumn dispersion from the injection process. Contrary to common 
practice, however, only small changes in the injection solvent composition are necessary to produce a marked improvement in the zone profile. When the injection solvent differs substantially from the mobile phase (i.e., pure water or acetone), deleterious changes in the zone profile are observed that are not presently predictable (5).

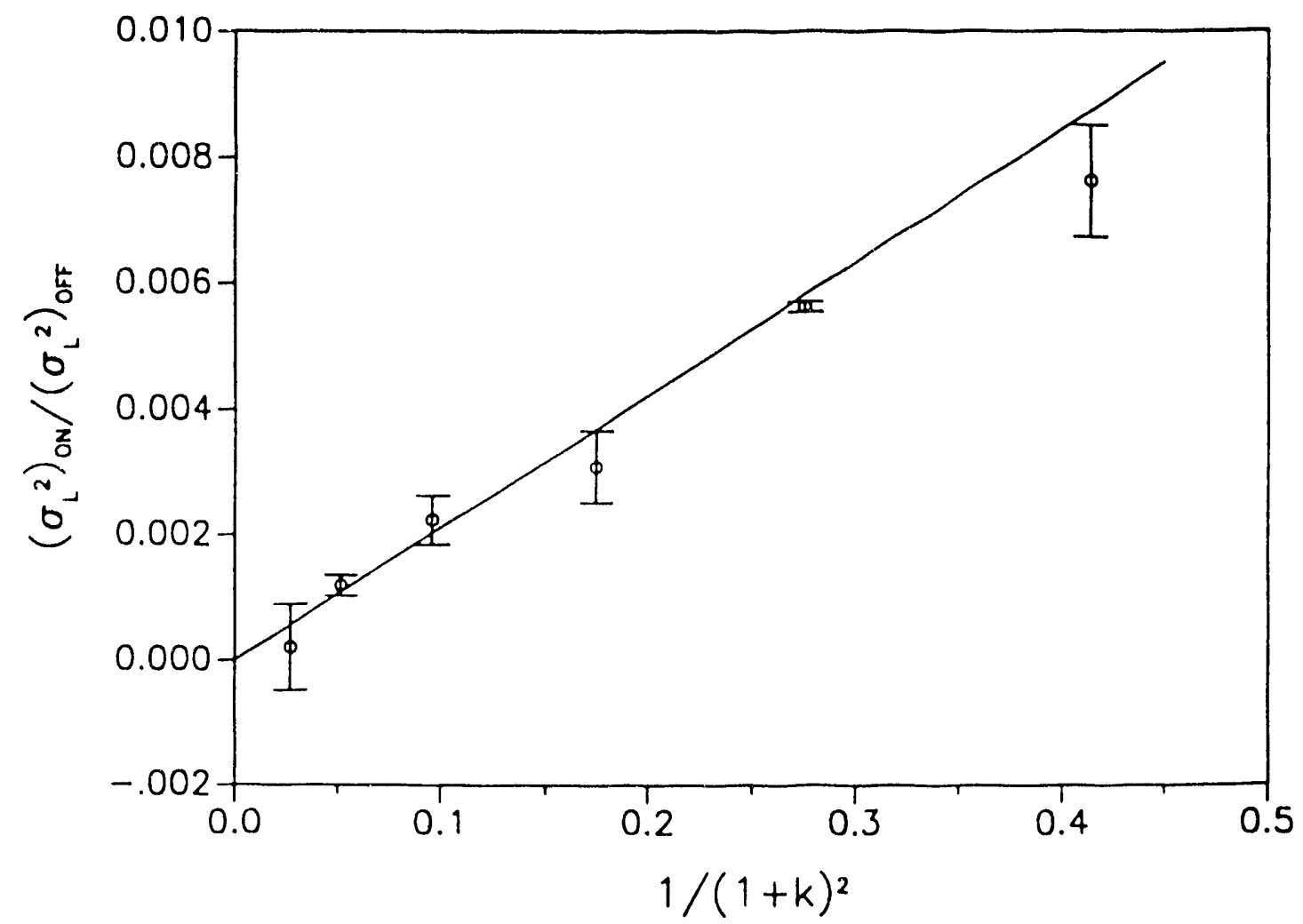

FIGURE 2: Measured ratio of the length variance measured off- and on-column after injection as a function of the capacity factor. ( - ) Theoretical prediction according to Equation [1]; ( $O$ ) Experimental measurement using a homologous series of fatty acids as model solutes (5).

\section{ELUTION NONEQUILIBRIUM}

Nonequilibrium effects are also significant at the exit of the chromatographic column, where the solute zone passes from the retentive packed bed to a nonretentive open tube or detector flowcell. Upon elution of the solute zone, an increase in length variance and a concomitant decrease in concentration are observed as a function of the capacity factor. This increase in variance may be predic ed theoretically using a simple steadystate model of the elution process developed in our laboratory $(6,7)$ :

$$
\left(\sigma_{L}^{2}\right)_{\text {OFF }}=\left(\sigma_{L}^{2}\right)_{O N} \frac{r^{4} O N}{r^{4} \text { OFF }} \varepsilon_{T}^{2} \quad\left(1+k_{M P}\right)^{2}
$$

where $\left(\sigma_{L}^{2}\right)_{O N}$ and $\left(\sigma_{L}^{2}\right)_{\text {OFF }}$ are the length variances measured directly on and immediately after the packed bed, respectively, and all other variables are as previously defined. Excellent agreement is observed between experimental measurements and theoretical predictions based on this model, as shown in Figure 3. 


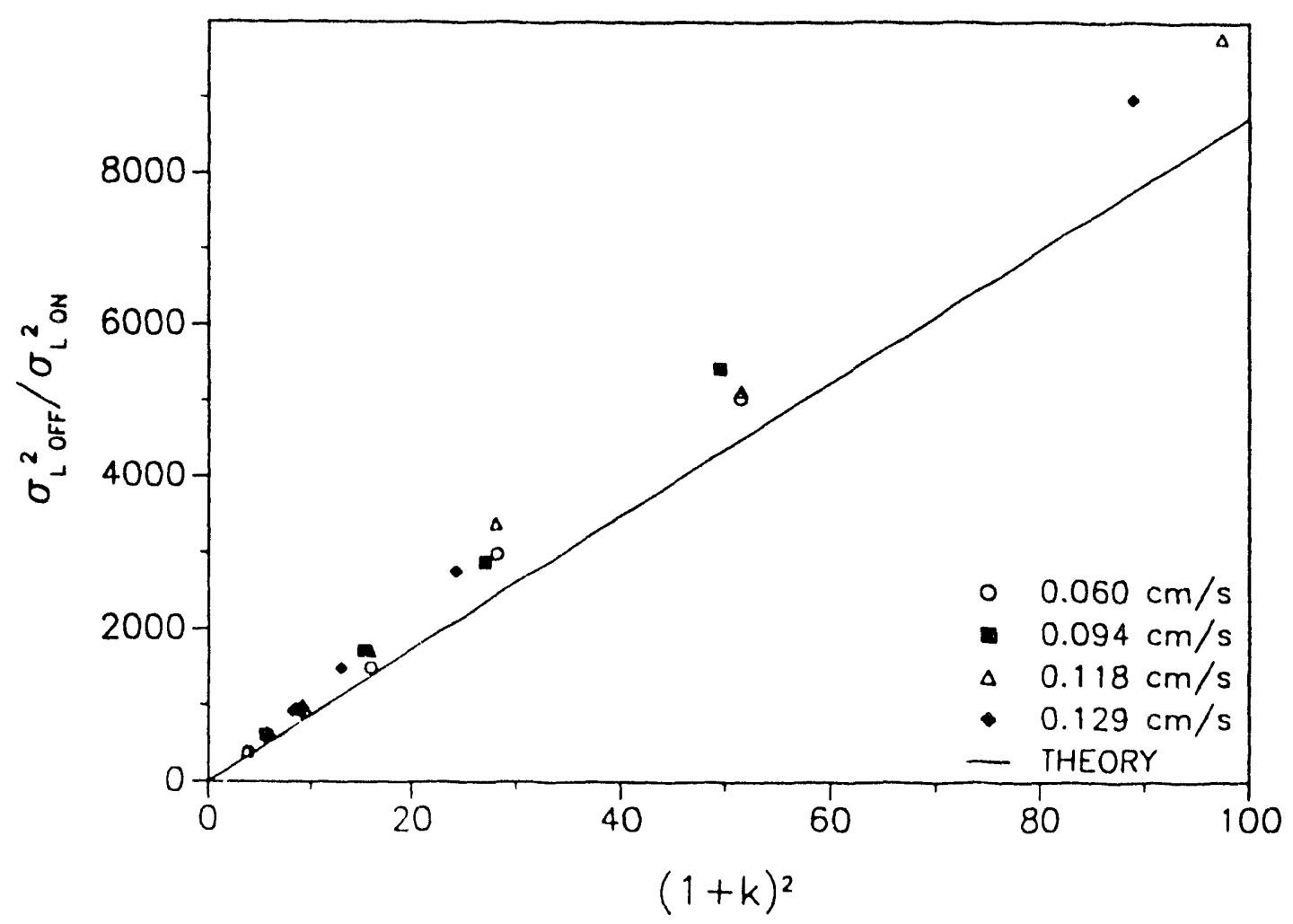

FIGURE 3: Measured ratio of the length variance measured on- and off-column after elution as a function of the capacity factor. Theoretical prediction according to Equation [2]. Experimental measurement with varying mobile-phase linear velocity using ? homologous series of fatty acids as model solutes $(6,7)$.

Because there is an abrupt change in retention that is propagated spatially and temporally along the solute zone profile, the steady-state model described above may not adequately represent this source of dispersion. Consequently, it is desirable to test this model under a variety of practical operating conditions where departure from equilibrium may be expected. In these studies, we have attempted to disrupt the local equilibrium by altering the linear velocity, temperature, and mobile-phase composition.

Although the linear velocity of the mobile phase is known to influence solute zone dispersion along the column, it is not implicated directly or indirectly in Equation [2]. If th ; steady-state model is correct, then the length variance ratio should be independent of linear velocity. This expectation is verified in Figure 3 for velocities near the optimum value ranging from 0.060 to $0.129 \mathrm{~cm} / \mathrm{s}$.

The thermodynamic partition coefficient and, hence, the capacity factor $(k)$ is inversely related to temperature according to the Van't Hoff equation (14). If the steady-state model is correct, this should be the only influence of temperature on elution nonequilibrium processes. Under steady-state conditions, Equation [2] predicts that a graph of the length variance ratio versus the function of capacity factor $(1+k)^{2}$ should be independent of temperature. This expectation is verified in Figure 4 for temperatures ranging from 25 to $90^{\circ} \mathrm{C}$, where capacity factors decrease three- to ten-fold for solutes $n-C_{10}$ to $n-C_{20}$, respectively. 


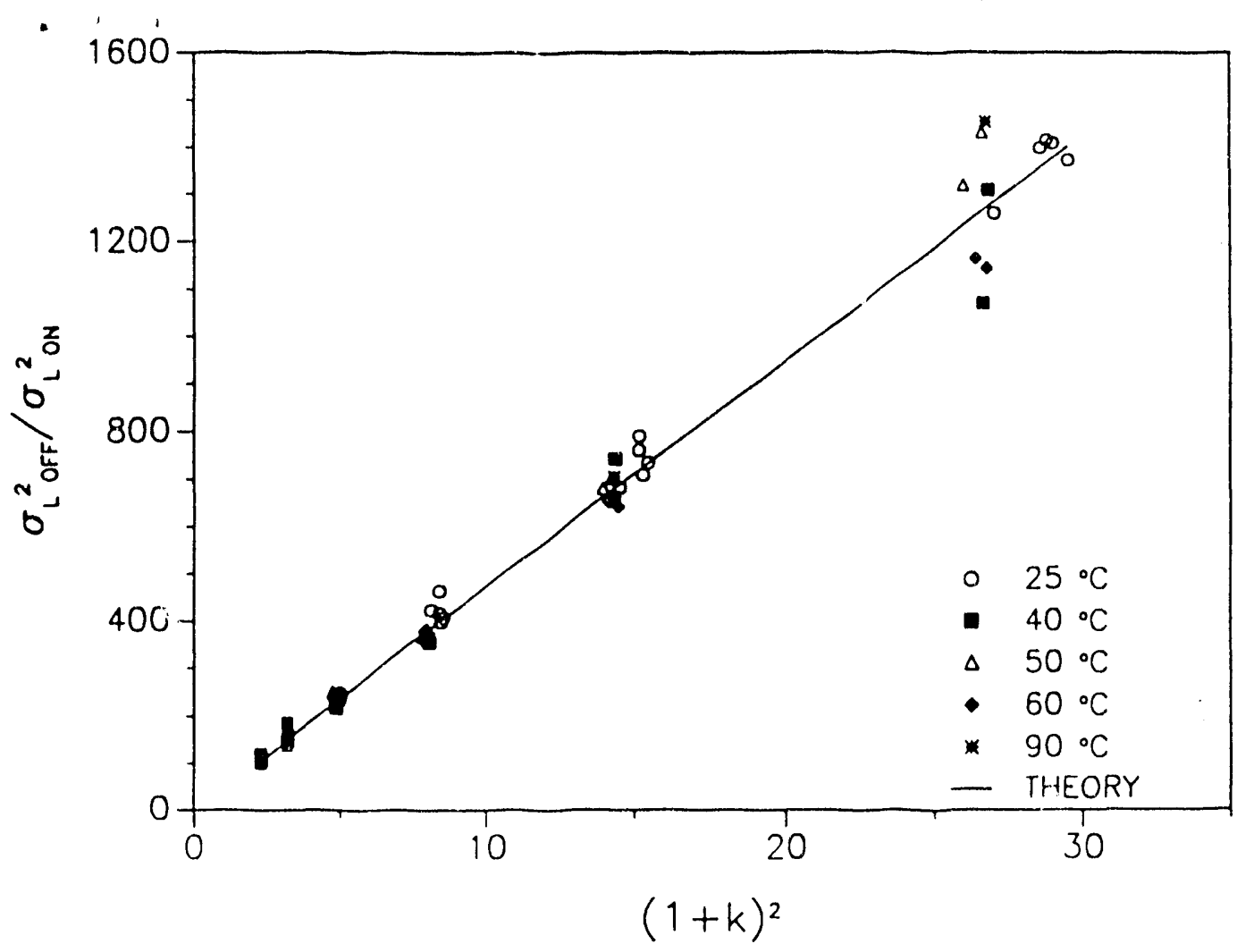

FIGURE 4: Measured ratio of the length variance measured on- and off-column after elution as a function of the capacity factor. Theoretical prediction according to Equation [2]. Experimental measurement with varying temperature using a homologous series of fatty acids as model solutes (7).

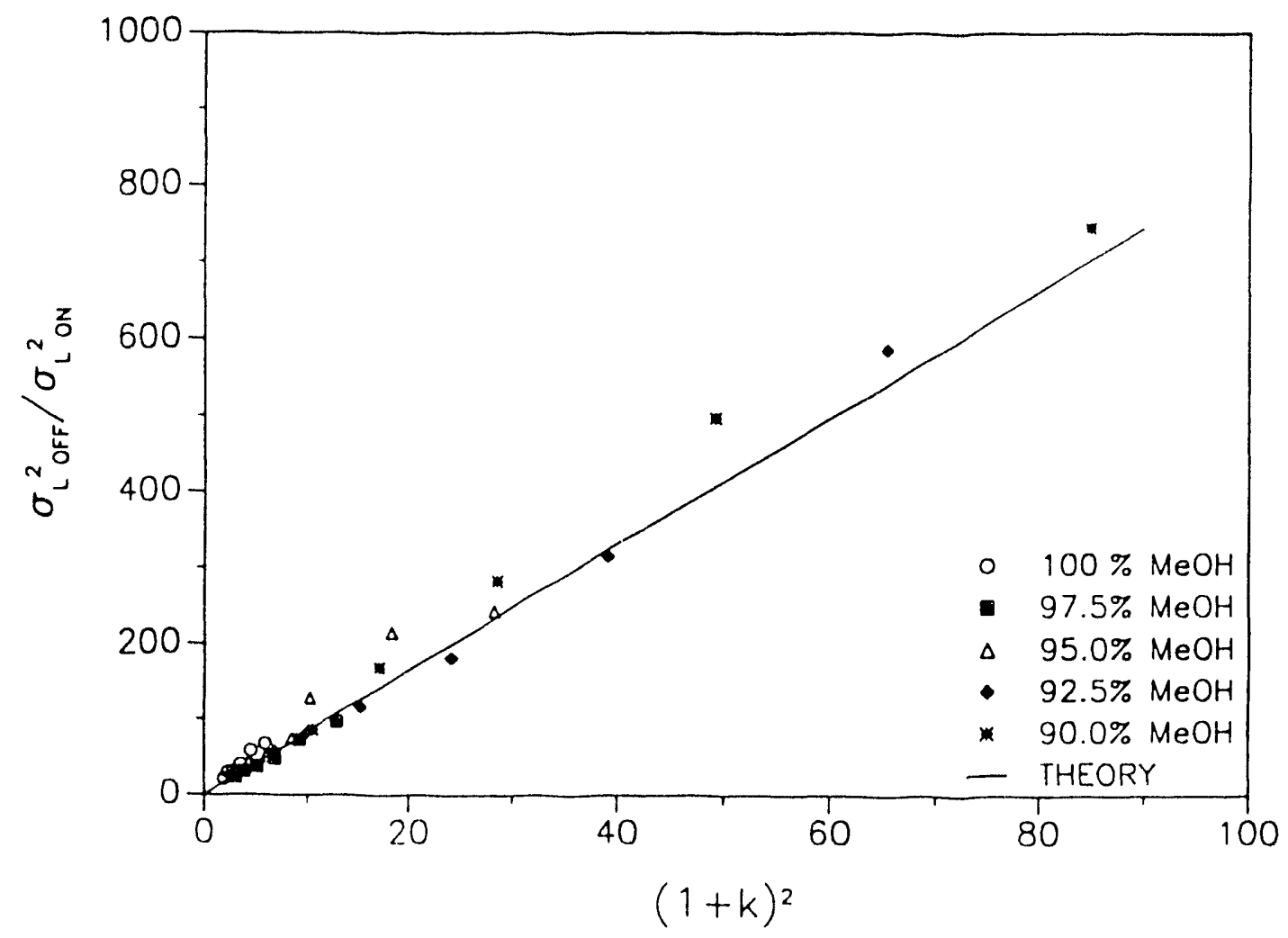

FIGURE 5: Measured ratio of the length variance measured on- and off-column after elutir $n$ as a function of the capacity factor. Theoretical prediction accurding to Equation [2]. Experimental measurement with varying mobile-phase composition using a homologous series of fatty acids as model solutes (7). 
Similarly, the mobile-phase composition is known to influence the solute capacity factor. According to regular solution theory, the logarithm of the capacity factor is quadratically related to the volume fraction of organic solvent in the mobile phase $(15,16)$. If this is the only influence of mobile-phase composition, Equation [2] predicts that a graph of the length variance ratio versus the function of capacity factor $(1+k)^{2}$ should be independent of composition. This expectation is verified in Figure 5 for mobile-phase compositions ranging from 90 to $100 \%$ methanol-water mixtures, where capacity factors decrease five- to fifteen-fold for solutes $n-C_{10}$ to $n-C_{20}$, respectively.

As shown in Figures $3-5$, the extent of solute zone broadening upon elution from the chromatographic column is substantial, and increases with the capacity factor as $1+$ k) ${ }^{2}$. The excellent agreement with Equation [2] indicates that, while nonequilibrium exists across the entire solute zone profile, at any spatial location the solute is in local thermodynamic equilibrium between the mobile and stationary phases. This observation suggests that a temporal gradient in temperature or mobile-phase composition would be expected to minimize this source of dispersion by reducing the capacity factors for late-eluting solutes, whereas a temporai gradient in linear velocity would not be effective in this manner. Furthermore, a spatial gradient in any of these variables would be ineffective to reduce this source of dispersion (7). Because this appears to be a substantial contribution to the general elution problem in chromatography, a more thorough understanding of this dispersion process is required. These studies are currently underway in our laboratory.

\section{SOLUTE RETENTION ALONG THE CHROMATOGRAPHIC COLUMN}

Several recent studies have demonstrated that solute retention and selectivity may be substantially altered by temperature $(17,18)$ and by pressure $(19,20)$. Whereas the previous studies have demonstrated the practical utility of these variables, correlation of experimental results with theoretical models has been notably lacking. There are several important problems that make the experimental data intractable to theoretical interpretation. First, radial and axial temperature gradients may develop in the chromatographic column due to the difference in heat capacity of the various components and due to the relatively slow rate of heat transfer and dissipation. Second, most studies in liquid chromatography are performed under conditions of constant flowrate. As the temperature is increased, the viscosity of the mobile phase is decreased and the pressure is concomitantly decreased. Thus, the experimental measurement of the effect of temperature on solute retention becomes convoluted with the effect of pressure. A third problem arises because detection in most chromatographic systems is performed at the end of the column. Under these conditions, retention measurements represent an average over the entire column length and, thus, an average from the inlet to the outlet pressure. Although a few studies have been performed by using a restricting valve at the outlet to maintain a small pressure differential along the column (19), this approach is not routine practice in liquid chromatography. In order to conduct experimental studies that are thermodynamically meaningful, temperature and pressure must be controlled and varied independently.

In this study, these problems are addressed by detecting the solute zones in situ along an optically transparent packed capillary column (8-10). Because of the small diameter of these columns, thermal equilibration is rapidly achieved so that temperature gradients are minimized. Thus, solute retention may be measured in small, isolated regions of the column wherein temperature and pressure are well known and do not vary substantially. These studies are performed using octadecylsilica, the most common stationary phase for liquid chromatography, making the results of widespread interest and applicability. 


\section{SOLUTE RETENTION AT VARYING TEMPERATURE AND CONSTANT PRESSURE}

The effect of temperature upon solute retention is described by the well-known Van't Hoff equation (14):

$$
\ln k=\ln K-\ln \beta=\frac{-\Delta G}{R T}-\ln \beta=\frac{-\Delta H}{R T}+\frac{\Delta S}{R}-\ln \beta
$$

where the capacity factor $(k)$ represents the thermodynamic equilibrium constant $(K)$ for the solute distributed between the mobile and stationary phases, compensated for the volumetric ratio of these phases $(\beta)$. The capacity factor is related to thermodynamic quantities such as the change in Gibbs free energy $(\Delta G)$, enthalpy $(\Delta H)$, and entropy $(\Delta S)$ that arise from the transfer of one mole of solute between phases at isothermal temperature (T). From Equation [3], it is apparent that the logarithm of tho capacity factor should be linearly related to the inverse temperature if the molar enthalpy and entropy are invariant. As illustrated in Figure 6, the fatty acid derivatives exhibit the expected linear behavior at temperatures less than $20^{\circ} \mathrm{C}$ and greater than $30^{\circ} \mathrm{C}$. The discontinuity in the Van't Hoff plot between 20 and $30^{\circ} \mathrm{C}$ has been noted previously by Mciel and Serpinet $(21,22)$ for other homologous series. They attributed this discontinuity to a phase transition of the octadecylsilica stationary phase, where the transition temperature is strongly influenced by the density of alkyl chains bonded to the silica surface.

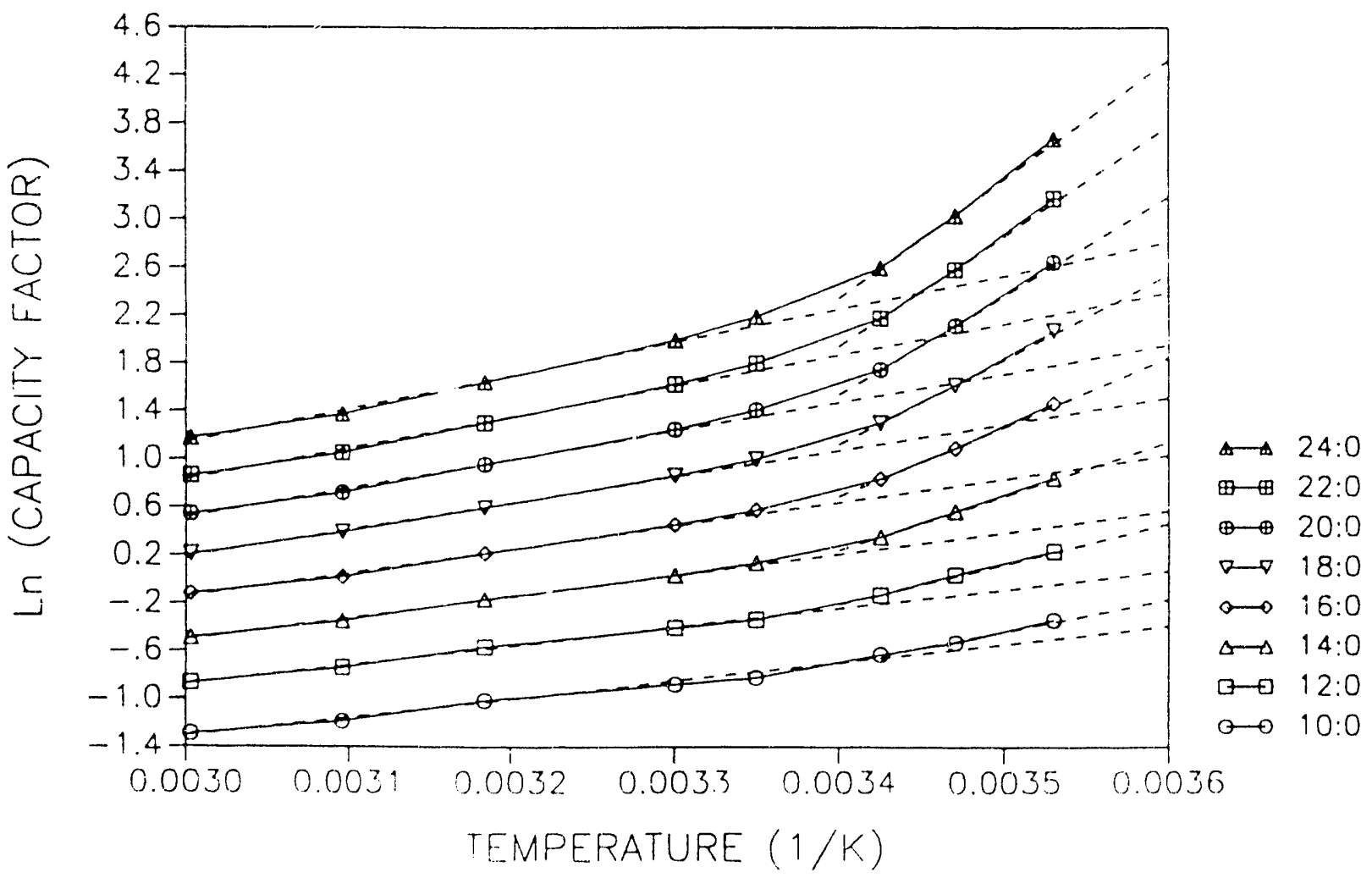

FIGURE 6: The logarithm of the capacity factor $(k)$ of derivatized fatty acids expressed as a function of the inverse temperature (9). 
According to Equation [3], the molar enthalpy of solute transfer between the mobile and stationary phases may be estimated from the slope of the Van't Hoff plot (In $k$ versus $1 / \mathrm{T}$ ) within the linear regions of Figure 6. As shown in Figure 7, the retention behavior is distinctly different in the temperature ranges jefore and after the phase transition. At temperatures greater than $30^{\circ} \mathrm{C}$, the enthalpy decreases linearly with carbon number. This result indicates that the cohesive attraction between solute and stationary phase increases uniformly with each additional ethylene group $\left(\mathrm{C}_{2} \mathrm{H}_{4}\right)$, as would be expected for van der Waal forces. However, a small but statistically significant discontinuity is observed between the homologues with carbon numbers 16 and 18 . Whereas the precise origin of this discontinuity remains in question, the explanation proposed by Tchapla et al. $(23,24)$ is intuitively reasonable and fully consistent with the experimental observations. If the stationary phase is extended and fully accessibie, solutes with short alkyl chains can be inserted completely into the stationary phase and, thus, have equal enthalpy per ethylene group. Solutes with alkyl chains longer than the stationary phase cannot penetrate fully, so that the remaining ethylene groups must interact by a different mechanism. From Figure 7 , the change in enthalpy per ethylene group for this second mechanism appears to be constant and of comparable magnitude to that for the original mechanism. At temperatures less than $20^{\circ} \mathrm{C}$, however, interpretation of the observed retention behavior is not so straightforward. The enthalpy decreases more rapidly with carbon number than in the high temperature range, arid the change in enthalpy per ethylene group does not remain constant. The shape of this curve is nearly sigmoidal, which indicates that the decrease in enthalpy becomes systematically greater in magnitude with each additional ethylene group until carbon number 16 to 18 , and becomes lesser thereafter.

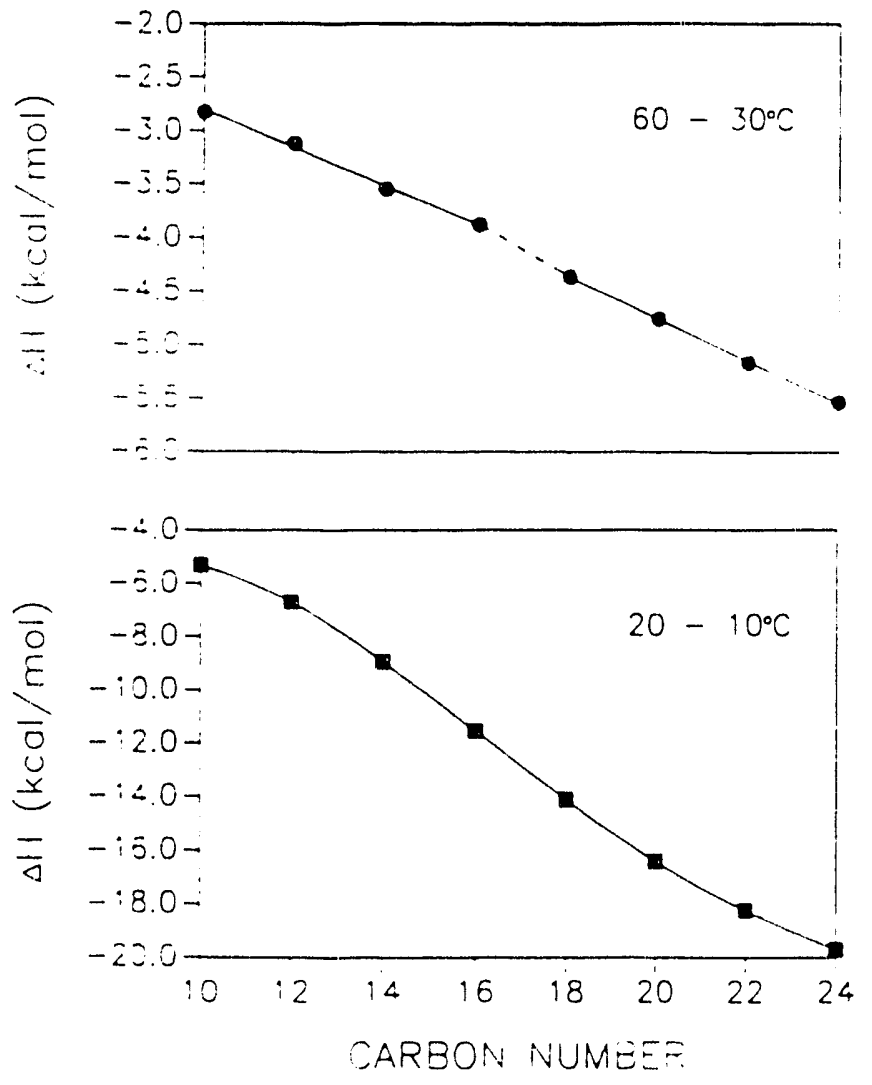

FIGURE 7: Molar enthalpy, calculated from Figure 6 in the high $\left(60-30^{\circ} \mathrm{C}\right)$ and low $\left(20-10^{\circ} \mathrm{C}\right)$ temperature ranges, expressed as a function of the carbon number of derivatized fatty acids (9). 
To gain a greater understanding of the thermodynamic differences in solute retention behavior, the enthalpy-entropy compensation temperature has been estimated by the method of Melander et al. (25). At temperatures greater than $30^{\circ} \mathrm{C}$, the compensation temperature was calculated to be 804 and $440^{\circ} \mathrm{C}$ for solutes with carbon numbers less than 16 and greater than 18, respectively. The relatively large magnitude of these values is consistent with previous reports $(24,25)$ and suggests that enthalpic contributions to retention are significantly more important than entropic contributions above the transition temperature. The entropic contribution is clearly more important for solutes with high carbon number, which supports the qualitative difference in retention mechanisms discussed by Tchapla et al. (24). At temperatures less than $20^{\circ} \mathrm{C}$, the compensation temperature was calculated to be 64 and $62{ }^{\circ} \mathrm{C}$ for solutes with carbon numbers less than 16 and greater than 18, respectively. It is apparent that entropic contributions to retention become very significant below the transition temperature and that this contribution is relatively independent of the solute chain length. The predominance of entropic contributions at subambient temperatures has been discussed previously by several research groups for bulky solutes such as planar and nonplanar polynuclear aromatic hydrocarbons $(17,18,26,27)$. However, it is apparent from the present study that entropic contributions are equally important for solutes that are of approximately the same size and shape as the octadecylsilica stationary phase. This observation suggests that the stationary phase is closely packed and very well ordered below the transition temperature. It is noteworthy, however, that the average area per octadecyl group is $47 \AA^{2}$ at a bonding density of $3.5 \mu \mathrm{mol} / \mathrm{m}^{2}$, which is more than two-fold greater than the average area for octadecanoic acid in Langmuir-Blodgeit films and related monolayer assemblies at their liquid-solid phase transition (28). Consequently, the octadecyl groups may not be distributed in a uniform mariner on the silica surface but, rather, may be clustered in regions of higher density more comparable to that of the monolayer films $\left(7.6 \mu \mathrm{mol} / \mathrm{m}^{2}, 22 \AA^{2}\right)$. This conclusion is supported by the very recent results of Wang and Harris (29), which indicate that the octadecylsilane groups are not permanently bonded to the silica surface but, rather, may migrate to form more stable assemblies.

\section{SOLUTE RETENTION AT VARYING PRESSURE AND CONSTANT TEMPERATURE}

From classical thermodynamics, the variation in the molar Gibbs free energy with pressure and temperature can be described by the difference between the change in molar volume $(\Delta V)$ with pressure and the change in molar entropy $(\Delta S)$ with temperature (14). Thus, the capacity factor may be expressed in the following manner:

$$
d(\ln k)=\frac{-d(\Delta G)}{R T}=\frac{-(\Delta V) d P}{R T}+\frac{(\Delta S) d T}{R T}
$$

if the volumetric ratio of the mobile and stationary phases $(\beta)$ does not vary with pressure and temperature. If temperature is maintained constant, then the last term in Equation [4] may be neglected. By integration of the remaining equation, it is evident that the logarithm of the capacity factor should increase linearly with pressure. This expected behavior is confirmed in Figure 8 for the pressure range from approximately 980 to 4430 psi. Although the magnitude is not entirely clear due to the logarithmic format of this graph, capacity factors increase by +9.3 to $+24.4 \%$ for solutes $n-C_{10}$ to $n$ $\mathrm{C}_{20}$, respectively $(8,9)$. 


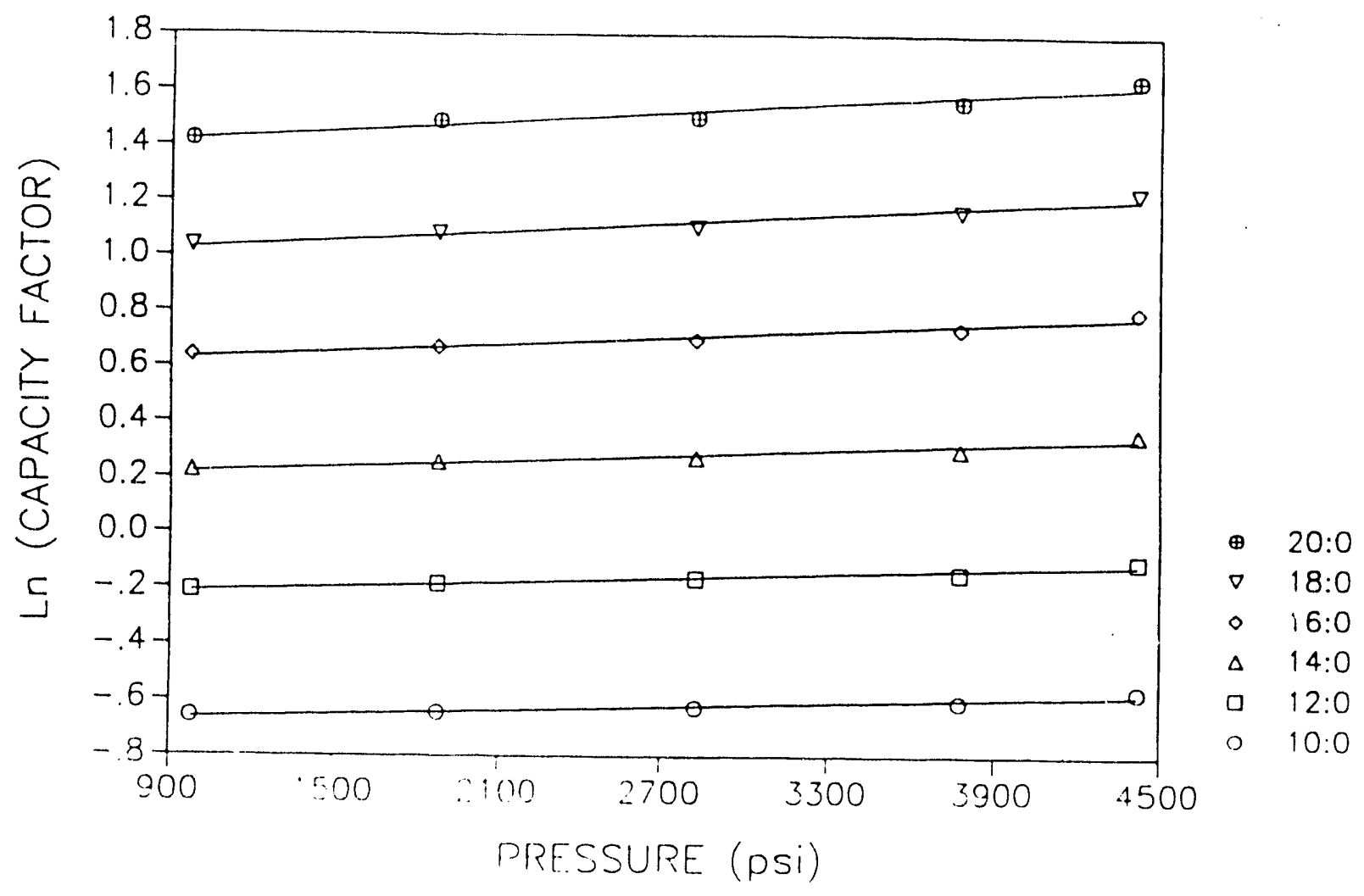

FIGURE 8: The logarithm of the capacity factor $(k)$ of derivatized fatty acids expressed as a function of pressure $(8,9)$.

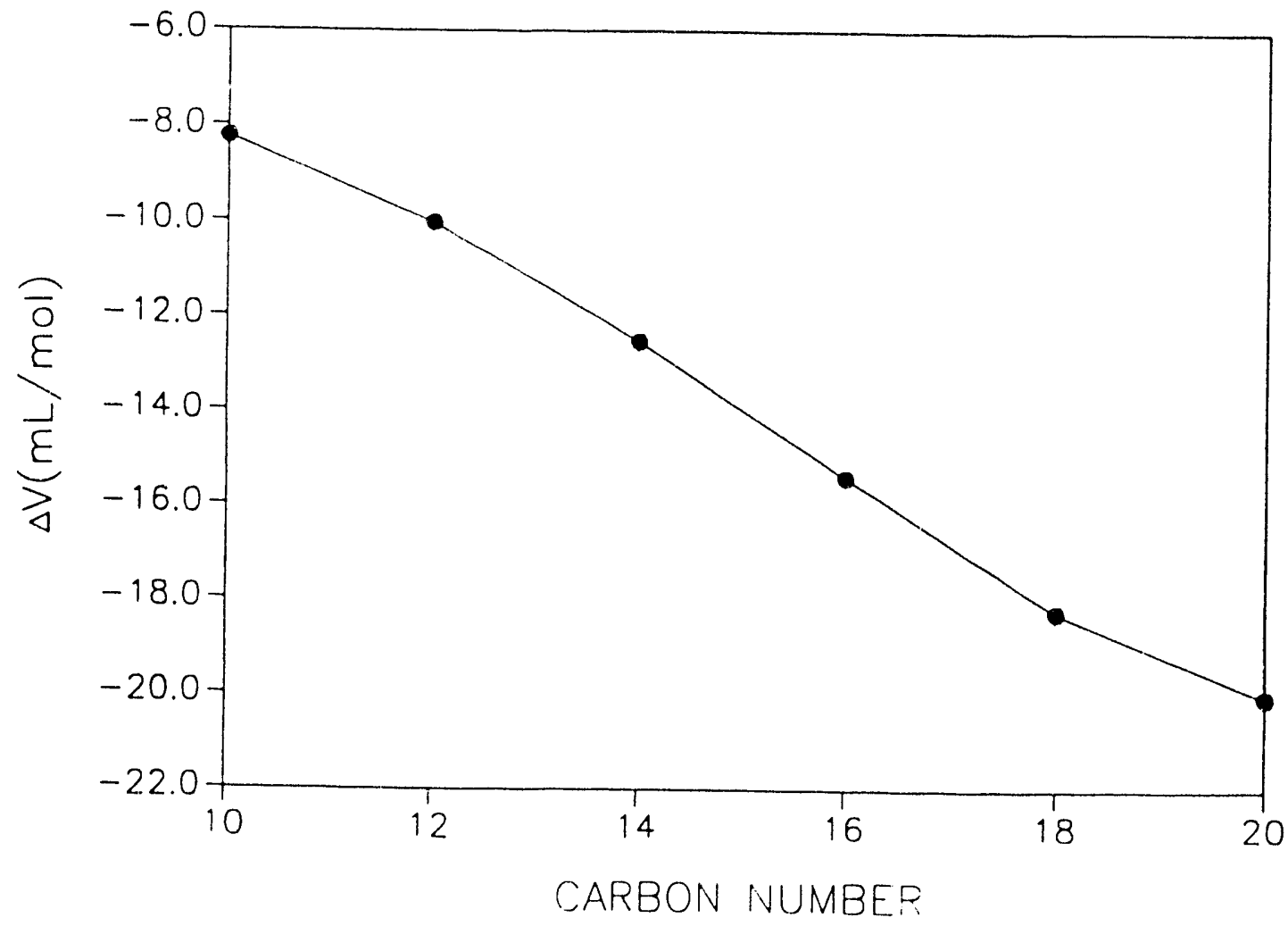

FIGURE 9: Molar volume, calculated from Figure 8, expressed as a function of the carbon number of derivatized fatty acids (9). 
According to Equation [4], the change in molar volume of the solute when transferred between the mobile and stationary phases may be estimated from the slope of the graph of In $k$ versus $P$ (Figure 8). As shown in Figure 9, the molar volume does not change uniformly for each successive ethylene group. The shape of this curve is nearly sigmoidal, which indicates that the decrease in molar volume becomes systematically greater with each additional ethylene group until carbon number 16 to 18, and becomes lesser thereafter. The similarity of these data to those shown in the bottom of Figure 7 suggest that the change in solute retention induced by pressure is most similar to the change induced by temperature below the transition temperature. Thus, the stationary phase becomes more rigid with decreasing temperature or with increasing pressure, and entropic contributions to retention are expected to become more significant.

\section{COMBINED EFFECT OF TEMPERATURE AND PRESSURE}

Based on the results presented above, the interrelationship between the effects of temperature and pressure on solute retention may now be elucidated. By differentiation of Equation [3], the variation in capacity factor with temperature at constant pressure is expressed as

$$
\left[\frac{\mathrm{d}(\ln k)}{\mathrm{dT}}\right]_{\mathrm{P}}=\frac{\Delta H}{R T^{2}}
$$

From the experimental data shown in Figure 6 , the values of $d(\ln k) / d T$ decrease systematically from -0.012 to $-0.029^{\circ} \mathrm{C}-1$ for solutes $n-C_{10}$ to $n-C_{20}$, respectively, when evaluated at 1700 psi.

From Equation [4], the variation in capacity factor with pressure at constant temperature is expressed as

$$
\left[\frac{\mathrm{d}(\ln k)}{\mathrm{dP}}\right]_{T}=\frac{-\Delta V}{\mathrm{RT}}
$$

From the experimental data shown in Figure 8 , the values of $\mathrm{d}(\ln \mathrm{k}) / \mathrm{dP}$ increase systematically from $+2.3 \times 10^{-5}$ to $+5.6 \times 10^{-5} \mathrm{psi}^{-1}$ for solutes $n-\mathrm{C}_{10}$ to $n-\mathrm{C}_{20}$, respectively, when evaluated at $28^{\circ} \mathrm{C}$.

The effects of temperature and pressure may be considered simultaneously by invoking the chain rule

$$
\left[\frac{d(\ln k)}{d T}\right]_{P}\left[\frac{d P}{d(\ln k)}\right]_{T}=-\left[\frac{d P}{d T}\right]_{\ln k}
$$

By substitution of Equations [5] and [6] into Equation [7],

$$
\left[\frac{\Delta H}{R T^{2}}\right]\left[\frac{R T}{-\Delta V}\right]=-\left[\frac{\Delta H}{T \Delta V}\right]
$$

These thermodynamic expressions, when evaluated at the temperature and pressure of a phase transition, represent the slope of the phase diagram and are a highly characteristic property of the medium. If $\mathrm{dP} / \mathrm{dT}$ is evaluated for a pure medium, then $\Delta \mathrm{H}$ and $\Delta \mathrm{V}$ represent the change in molar enthalpy and molar volume of that medium. 
In the chromatographic measurements, however, these thermodynamic parameters represent the change in molar enthalpy and volume of the solute transferred between the mobile phase and the stationary phase that is undergoing the phase transition. Consequently, it is necessary that the solute have physical and thermodynamic properties similar to those of the stationary phase for this calculation to be meaningful. The values of $(\mathrm{dP} / \mathrm{dT})_{\ln \mathrm{k}}$ are approximately equal $\left(520 \pm 20 \mathrm{psi} /{ }^{\circ} \mathrm{C}\right)$ for all of the fatty acid derivatives. From the mean value, we may deduce that a 520 psi change in pressure will produce approximately the same change in solute retention as a $1^{\circ} \mathrm{C}$ change in temperature when the stationary phase is at the phase transition.

An interesting and important analogy can be developed by comparing the thermodynamic properties of the octadecylsilica stationary phase at the phase transition with those of two relevant model systems. Although neither of these systems is directly comparable to the surface-bonded stationary phase, they may be thought to serve as limiting models for comparison. The first model system is the randomly oriented alkane solvent, n-octadecane, for which the melting temperature is $30.7^{\circ} \mathrm{C}$ at $1700 \mathrm{psi}$ and the $\mathrm{dP} / \mathrm{dT}$ value is $580 \mathrm{psi} /{ }^{\circ} \mathrm{C}(30)$. The second model system is the highly ordered phospholipid bilayer, dimyristoylphosphatidylcholine, for which the melting temperature is $28.7^{\circ} \mathrm{C}$ at $1700 \mathrm{psi}$ and the $\mathrm{dP} / \mathrm{dT}$ value is $360 \mathrm{psi} /{ }^{\circ} \mathrm{C}(31)$. From these results, we may conclude that the octadecylsilica stationary phase is more similar in thermodynamic behavior to a randomly oriented bulk alkane than a highly ordered system such as a phospholipid membrane.

The phase diagram of $n$-octadecane has been reconstructed from literature data $(30)$ in Figure 10, and the temperature/pressure locus of retention measurements examined in this study are superimposed on this diagram. By using the statistical method of cluster analysis, we have verified that the retention measurements within the liquid and solid regions of this phase diagram belong to two distinct classes.

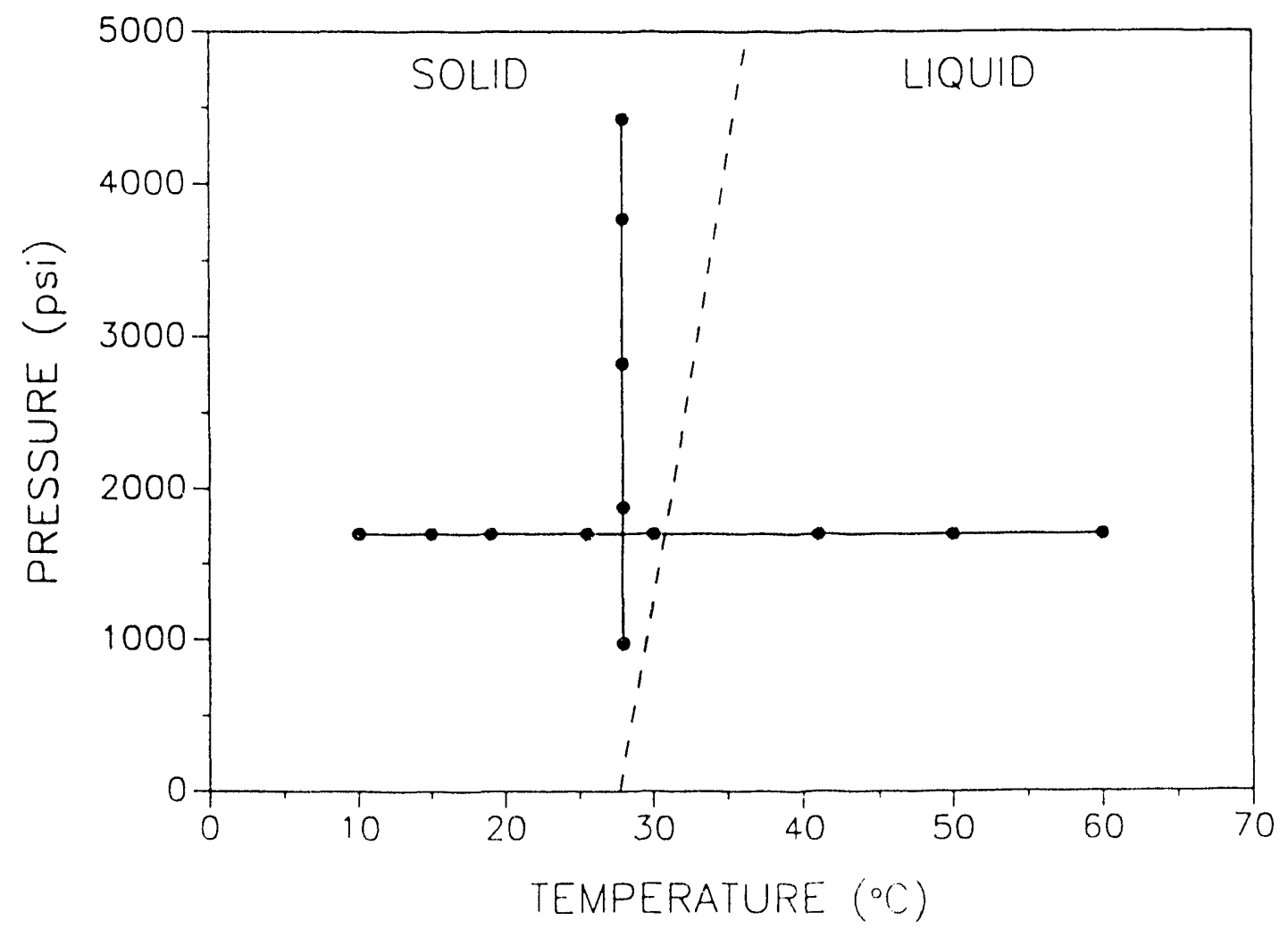

FIGURE 10: Diagram showing temperature/pressure locus of retention measuiements for this study, superimposed upon a phase diagram of n-octadecane (9). 
It is evident that the phase oundary is well within the range of routine operating conditions in liquid chromatography and that a transition may be readily induced by a change in either temperature or pressure. The practical consequences of this observation merit a more detailed discussion. At ambient temperature, octadecylsilica is likely to undergo this phase transition at some position along the length of the column. The exact position where the phase transition occurs, will depend upon the local pressure and, hence, upon the physical properties of the packed bed as well as those of the mobile phase. Therefore, as the solutes traverse the column, their retention and selectivity will be determined initially by the thermodynamic properties of the solid-like phase (more entropic), and later by the properties of the liquid-like phase (more enthalpic). The thermodynamic properties will be continually altered during routine use of the column through loss of bonded stationary phase and through irreversible retention of solutes. The practical consequence of this behavior is that retention measurements will be imprecise and resolution will vary unpredictably. A potential solution to this problem is to employ higher or lower temperatures, so that the pressure gradient cannot induce a phase transition along the column length. A more rational and permanent solution would be to employ stationary phases whose phase transitions are outside the range of routine operating conditions, for example tetradecyl- or docosylsilica. Clearly, more detailed theoretical and experimental studies will be required in order to understand the thermodynamic behavior of these alkylsilica stationary phases more completely.

\section{SOLUTE DISPERSION ALONG THE CHROMATOGRAPHIC COLUMN}

The theory of hydrodynamics in open-tubular columns, with their clean and simple geometry, is well established and well accepted. The relative contributions to dispersion by longitudinal diffusion and mass transfer in the mobile and stationary phases are completely and exactly known from the work of Golay (43) and others. The correlation of experiment and theory is possible because the assumptions inherent in the theoretical model (perfectly circular column cross-section, constant diameter along column length, thin and uniform film of stationary phase, constant linear velocity in the laminar flow regime, constant temperature and pressure, etc.) can be experimentally achieved. Consequently, an accurate mathematical description of the hydrodynamics in open-tubular columns is possible.

For packed columns, this is simply not the case. The structure of a real packed bed is irregular, rather than one of the well-characterized models such as cubic or hexagonal close-packed structures. More importantly, the packing structure and density are known to vary along the column diameter and length over both short-range $(\mu \mathrm{m})$ and longrange $(\mathrm{mm}$ to $\mathrm{cm})$ distances. As a result, the linear velocity is not constant and, because of the abrupt change in dimension of the fluid channels between particles, is not likely to be fully laminar. Other assumptions concerning the packing material itself (perfectly spherical particles, uniform diameter and density, either no pores or perfectly cylindrical pores, physically and chemically homogeneous stationary phase, etc.) contribute to an unrealistic representation of the packed bed. As a result, the most mathematically rigorous hydrodynamic equations are not practically useful because the assumptions of the model cannot be met experimentally (13). Consequently, most hydrodynamic theories currently in use for packed columns are predictive parametric models; that is, an equation of the generally accepted form is modified with empirically derived fitting constants (44). For example,

$$
H=\sigma_{L}^{2} / L=A+B / U+C u
$$

where $H$ is the theoretical plate height (length variance per unit column length), $u$ is the linear velocity, and $A, B$, and $C$ are the fitting constants for contributions from multiple paths, longitudinal diffusion, and mass transfer, respectively. Although the exact form of the equation may differ among the currently accepted models, the empirical and predictive nature does not. This approach is valuable in comparing performance for different columns and for different chromatographic conditions; however, it reveals nothing about the correctness of the theoretical model, since nearly any experimental data can be fit to an equation of these general forms. 
By using the on-column detection approach, hydrodynamic dispersion can be accurately measured in situ along the chromatographic column. This approach has been validated using open-tubular columns and, to date, variances as small as $10 \mathrm{~nL}^{2}$ have correlated accurately with theoretical models (4). From our previous studies, we have gained experience in the preparation and characterization of uniformly packed beds of spherical particles. We have acquired a clear understanding of the retention and dispersion processes that occur as solute zones enter $(5)$ and exit $(6,7)$ the packed bed. Finally, we have elucidated the retention behavior of solute zones as a function of local temperature and pressure along the packed bed (8-10). Given this fundamental knowledge, we are now able to make accurate and meaningful measurements of hydrodynamic dispersion as a function of spatial position along the chromatographic column.

We have recently completed the acquisition of dispersion measurements for the derivatized fatty acids under the experimental conditions described previously. These measurements are presently under evaluation, whereby plate height versus lines. velocity graphs are in preparation for each solute. These graphs, and the hydrodynamic data derived therefrom, may then be compared with the most rigorous theoretical models (13). Two features in this comparison are of particular interest: First, we wish to examine the dependence of longitudinal diffusion and mass transfer contributions on temperature and pressure. While this dependence has been addressed for gas and supercritical-fluid chromatography $(13,32,33)$, it has not been adequately characterized in liquid chromatography. This dependence becomes particularly important if the stationary phase undergoes a phase transition along the chromatographic column (vide supra). Second, we will examine the dependence of the mobile- and stationary-phase mass transfer contributions on the capacity factor. While many forms of this dependence have been proposed for packed beds $(13,44,45)$, none of them has been conclusively proven to be correct. We anticipate that comparison of the experimental data with theoretical models will be completed within the present project year.

\section{RELATED STUDIES}

In addition to the studies described above, significant progress has been made in several related areas of research supported by the Department of Energy. These studies will be briefly described below.

\section{DETERMINATION OF PHYSIOLOGICALLY IMPORTANT FATTY ACIDS}

The polyunsaturated omega-3 fatty acids such as eicosapentaenoic and docosahexaenoic acids are highly enriched in fish oil extracts from cod, mackerel, sardine, and menhaden (46). These extracts are commonly ingested as dietary supplements because of their putative therapeutic benefits. Several clinical studies have shown that the administration of fish oils to humans and animals can produce antihypertensive, antihyperlipidemic, and antiaggregatory effects $(46,47)$. However, these fish oil extracts may contain other saturated and unsaturated fatty acids whose physiological effects are less beneficial or are not fully understood. Consequently, the identification and quantitation of all constituents is an important problem for clinical studies as well as for routine evaluation of commercially available dietary supplements.

In this study (51), the retention behavior of the 4-bromomethyl-7-methoxycoumarin derivatives of fatty acids with 12-22 carbon atoms and 0-6 double bonds has been 
studied on octadecylsilica stationary phase using aqueous methanol and acetonitrile mobile phases. By using the saturated fatty acids for comparison, the Kovats retention index (l) of unsaturated fatty acids can be calculated under specified experimental conditions in the following manner $(48,49)$ :

$$
1=100\left[N+\frac{\log \left(k_{i} / k_{N}\right)}{\log \left(k_{N+1} / k_{N}\right)}\right]
$$

where $k$ is the capacity factor for the unsaturated fatty acid (i) that elutes between the saturated fatty acids with carbon numbers $N$ and $N+1$. Because the unsaturated fatty acids are expressed in terms of the chain length of an equivalent saturated fatty acid, the Kovats retention index is conceptually analogous to the classical ECL model of Özcimder and Hammers (50). These models are mathematically related in the following manner:

$$
1 / 100=E C L=N-y n
$$

where ECL is the equivalent chain length, $N$ is the number of carbon atoms, $n$ is the number of double bonds, and $y$ is an empirically derived coefficient. To determine the values of the coefficient under specified experimental conditions, the retention index values for the fatty acids were substituted into Equation [22] and analyzed by linear regression. The experimentally measured and theoretically predicted values for the retention index of each unsaturated fatty acid are summarized in Table VI. Although the average error incurred by using Equation [22] appears to be rather small $(1.83 \%$ relative error), it is significantly greater than the precision of replicate measurements $( \pm 0.1 \%$ relative standard deviation). More importantly, however, this error results in the incorrect prediction of elution order for all of the polyunsaturated fatty acids with retention characteristics similar to saturated and monounsaturated fatty acids (Table VI).

From our studies, an improved empirical equation to describe and predict the retention behavior of unsaturated fatty acids has been developed (51). For fatty acids with the same number of carbon atoms, the retention index was found to be linearly correlated to the number of double bonds $(n)$. Similarly for fatty acids with the same number of double bonds, the retention index was found to be linearly correlated to the number of carbon atoms. Based on these observations, a simple linear relationship may be derived:

$$
1 / 100=x N-y n+z
$$

where $x, y$, and $z$ are empirically derived coefficients. To determine the values of these coefficients under specified experimental conditions, the retention index values for the fatty acids were substituted into Equation [23] and analyzed by multiple linear regression. As summarized in Table VI, all fatty acids are predicted in the correct elution order and the average error in the retention index is $0.46 \%$.

Based on these theoretical studies, an optimized analytical method has been developed to separate the saturated and unsaturated fatty acids in fish oil dietary supplements. The regression coefficients for Equation [23] were determined as a function of composition for aqueous methanol and acetonitrile mobile phases. From these regression equations, the overlapping resolution map technique $(52,53)$ was used to determine the optimum mobile phase composition. Baseline resolution $\left(R_{s}=1.5\right)$ was achieved for all model fatty acids by using a packed capillary column with 240,000 theoretical plates and a mobile-phase composition of $90 \%$ methanol, $2 \%$ acetonitrile, and $8 \%$ water. The fatty acid derivatives were determined at the femtomole level in fish 
oil dietary supplements with laser-induced fluorescence detection. As shown in Figure 17, the dietary supplements contain predominantly the polyunsaturated eicosapentaenoic (20:5) and docosahexaenoic (22:6) acids as well as lesser amounts of hexadecatetraenoic (16:4) and octadecatetraenoic (18:4) acids. However, they may also contain significant amounts of saturated and monounsaturated fats such as myristic (14:0), palmitic (16:0), palmitoleic (16:1), and oleic (18:1) acids, which are of questionable health benefit.

TABLE VI: Comparison of experimental and theoretical retiontion indices (l) for unsaturated fatty acid derivatives (51).

\begin{tabular}{|c|ccccc|}
\hline & \multicolumn{5}{|c|}{ RETENTION INDEX (I) } \\
SOLUTE & Experiment & $\begin{array}{c}\text { Theory } \\
\text { Equation [22] }\end{array}$ & $\begin{array}{c}\text { Relative } \\
\text { Error } \\
(\%)\end{array}$ & $\begin{array}{c}\text { Theory } \\
\text { Equation [23] }\end{array}$ & $\begin{array}{c}\text { Relative } \\
\text { Error } \\
(\%)\end{array}$ \\
\hline $16: 4$ & 1064 & 1032 & -3.10 & 1059 & -0.47 \\
$16: 3$ & 1171 & 1174 & +0.26 & 1177 & +0.51 \\
$14: 1$ & 1228 & 1258 & +2.44 & 1229 & +0.08 \\
$18: 4$ & 1238 & 1232 & -0.49 & 1243 & +0.48 \\
$16: 2$ & 1292 & 1316 & +1.86 & 1295 & +0.23 \\
$20: 5$ & 1312 & 1291 & -1.60 & 1309 & -0.23 \\
$18: 3$ & 1358 & 1374 & +1.18 & 1361 & +0.22 \\
$22: 6$ & 1388 & 1349 & -2.81 & 1375 & -0.94 \\
$16: 1$ & 1419 & 1458 & +2.75 & 1414 & -0.35 \\
$20: 4$ & 1424 & 1432 & +0.56 & 1427 & +0.21 \\
$18: 2$ & 1475 & 1516 & +2.78 & 1480 & +0.34 \\
$22: 5$ & 1486 & 1491 & +0.34 & 1493 & +0.47 \\
$20: 3$ & 1532 & 1574 & +2.74 & 1546 & +0.91 \\
$18: 1$ & 1613 & 1658 & +2.79 & 1598 & -0.93 \\
\hline AVERAGE & & & 1.83 & & 0.46 \\
\hline
\end{tabular}

a Calculated from the equation $1 / 100=\mathrm{N}-1.419 \mathrm{n}$

b Calculated from the equation $1 / 100=0.922 N-1.184 n+0.570$ 


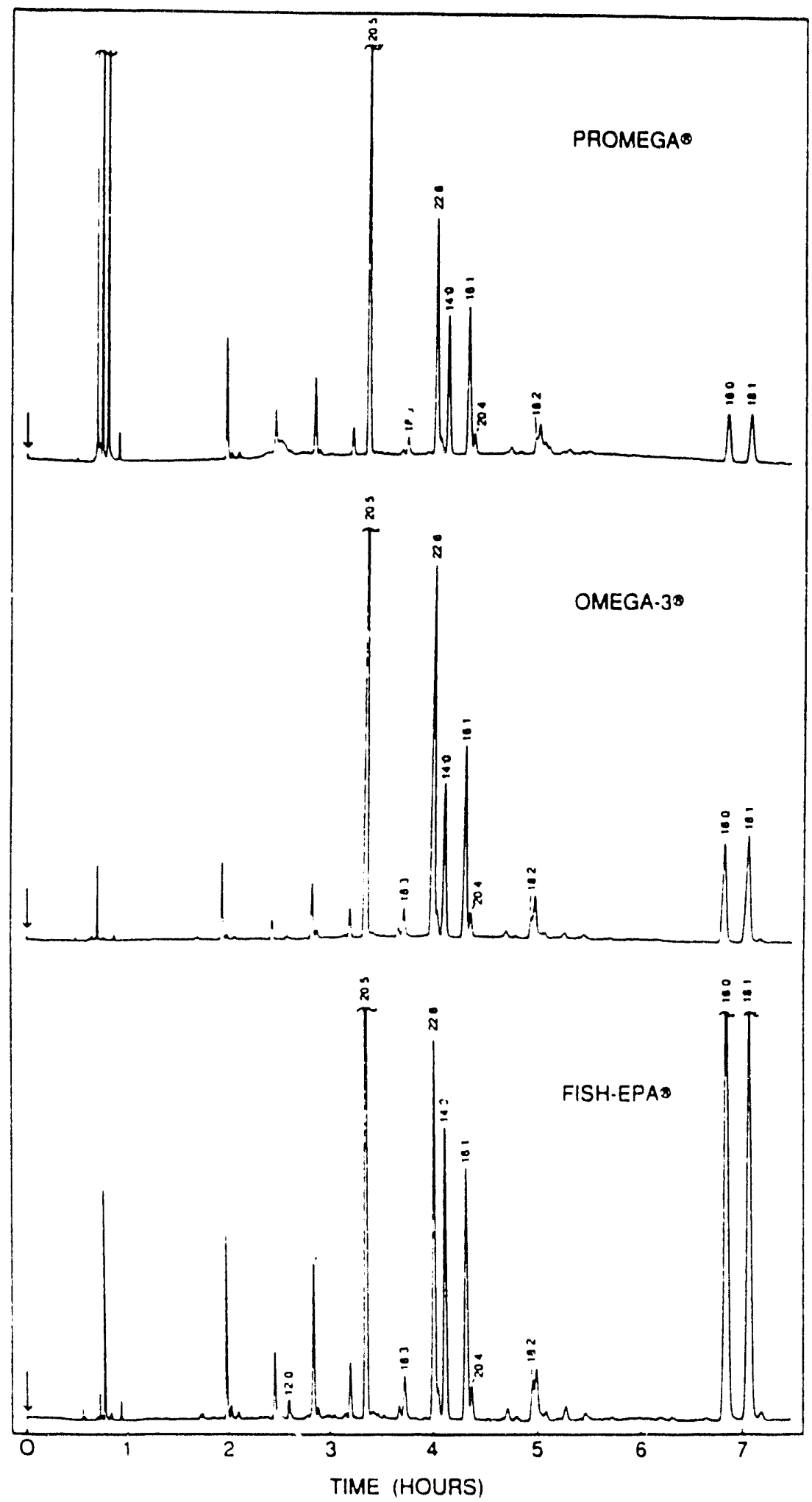

FIGURE 17: High-efficiency separation of fatty acid constituents at the femtomole level in commercially available fish oil dietary supplements (51). 
In summary, we believe that we have accomplished all of the primary scientific objectives of this research project (vide supra). We have constructed and evaluated a laser-induced fluorescence detection system that allows direct examination of the chromatographic column. We have utilized this system to examine nonequilibrium processes that occur upon solute injection and elution, and have developed a steadystate model that accurately describes these processes. We have also examined solute retention as a function of temperature and pressure, and have developed a thermodynamic model that accurately describes these processes. We are now examining solute zone dispersion as a function of temperature and pressure, and expect to complete these studies within tr a current project year. In each of these studies, substantial knowledge has been gained of the fundamental processes arising in chromatographic separations.

In addition to these primary research objectives, we have made significant progress in three related areas. First, we have examined pyrene as a fluorescent polarity probe in supercritical fluids and liquids as a function of temperature and pressure. By comparison with a computer simulation model, we found that the anomalous behavior of this probe arises from strong electrostatic interactions with dipolar and quadrupolar solvents. We have also developed methods for the class-selective identification of polynuclear aromatic hydrocarbons in coal-derived fluids by microcolumn liquid chromatography with fluorescence quenching detection. By comparison with the computer simulation model, we found that the Stern-Voimer constants may be predicted from the electrostatic interaction energy between the fluorophore and quenching agent. Finally, we have developed an optimized method for the determination of saturated and unsaturated (including omega-3) fatty acids in fish oil extracts by microcolumn liquid chromatography with laser-induced fluorescence detection. These additional studies extend the advanced separation and detection techniques developed in our laboratory to practical applications of environmental and biomedical significance.

\section{REFERENCES}

1. R. Simpson, S. Abbott; Varian Instrument Group, Walnut Creek, CA; personal communication (1988).

2. J.C. Gluckman, A. Hirose, V.L. McGuffin, M. Novotny; Chromatographia 17, 303 (1983).

3. C.E. Evans, V.L. McGuffin; Proc. Int. Symp. Capillary Chromatogr. 11, 802 (1990).

4. C.E. Evans, V.L. McGuffin; Anal. Chem. 60, 573 (1988).

5. C.E. Evans, V.L. McGuffin; Anal. Chem. 63, 1393 (1991).

6. $\quad$ C.E. Evans, V.L. McGuffin; J. Liq. Chromatogr. 11, 1907 (1988).

7. C.E. Evans, J.S. Yoo, V.L. McGuffin; Anal. Chem., manuscript in preparation.

8. V.L. McGuffin, C.E. Evans; J. Microcol. Sep. 3, 513 (1991).

9. V.L. McGuffin, C.E. Evans, S.H. Chen; J. Microcol. Sep., in press (1992).

10. C.E. Evans, S.H. Chen, V.L. McGuffin; Anal. Chem., accepted for publication.

11. J.C. Sternberg; Adv. Chromatogr. 2, 205 (1966).

12. V.L. McGuffin, R.N. Zare; Appl. Spectrosc. 39, 847 (1985).

13. J.C. Giddings; Dynamics of Chromatography; Marcel Dekker: New York, NY (1965).

14. P.W. Atkins; Physical Chemistry; W.H. Freeman and Co.: San Francisco, CA (1978).

15. P.J. Schoenmakers, H.A.H. Billiet, L. de Galan; Chromatographia 15, 205 (1982).

16. J.G. Dorsey, K.A. Dill; Chem. Rev. 89, 331 (1989).

17. J. Chmielowiec, H. Sawatzky; J. Chromatogr. Sci. 17, 245 (1979).

18. K.B. Sentell, A.N. Henderson; Anal. Chim. Acta 246, 139 (1991).

19. B.A. Bidlingmeyer, R.P. Hooker, C.H. Lochmuller, L.B. Rogers; Separ. Sci. 4, 439 (1969).

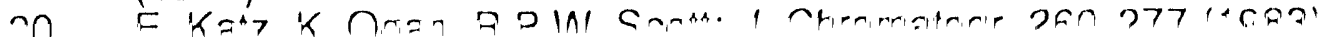


21. D. Morel, J. Serpinet; J. Chromatogr. 248, 231 (1982).

22. D. Morel, J. Serpinet, J.M. Letoffe, P. Claudy; Chromatographia 22, 103 (1986).

23. A. Tchapla, H. Colin, G. Guiochon; Anal. Chem. 56, 621 (1984).

24. A. Tchapla, S. Heron, H. Colin, G. Guiochon; Anal. Chem. 60, 1443 (1988).

25. W. Melander, D.E. Campbell, C. Horvath; J. Chromatogr. 158, 215 (1978).

26. L.C. Sander, S.A. Wise; Anal. Chem. 59, 2309 (1987).

27. L.C. Sander, S.A. Wise; LC-GC Magazine 8, 378 (1990).

28. G. Roberts; Langmuir-Blodgett Films; Plenum Press: New York, NY (1990).

29. H. Wang, J.M. Harris; J. Phys. Chem., submitted for publication (1992).

30. R.R. Nelson, W. Webb, J.A. Lixon; J. Chem. Phys. 33, 1756 (1960).

31.

32.

33. D.E. Martire, R.E. Boehm; J. Phys. Chem. 91, 2433 (1987).

34. J.H. Hildebrand, R.L. Scott; Solubility of Nonelectrolytes; Reinhold: New York, NY (1950).

35. D.E. Martire, D.C. Locke; Anal. Chem. 43, 68 (1971).

36. P.G. Tait; Scientific Papers, Vol. 2; University Press: Cambridge, England (1900); pp. 343-348.

37. R.C. Reid, J.M. Prausnitz, T.K. Sherwood; The Properties of Gases and Liquids; McGraw-Hill: New York, NY (1977).

38. W.L. Jorgenson, M. Ibrahim; J. Am. Chem. Soc. 104, 373 (1982).

39. S.W. Benson; J. Chem. Phys. 15, 367 (1947).

40. K.B. Sentell, J.G. Dorsey; Anal. Chem. 61, 930 (1989).

41. L.A. Cole, J.G. Dorsey; Anal. Chem. 64, 1317 (1992).

42. B. Buszewski, Z. Suprynowicz, P. Staszczuk, K. Albert, B. Pfleiderer, E. Bayer; J. Chromatogr. 499, 305 (1990).

43. M.J.E. Golay; Gas Chromatography 1958; D.H. Desty, Ed., Academic Press: New York, NY (1958); p. 36.

44. E. Grushka, L.R. Snyder, J.H. Knox; J. Chromatogr. Sci. 13, 25 (1975).

45. J.C. Giddings; Anal. Chem. 35, 439 (1963).

46. W.E.M. Lands; Fish and Human Health; Academic Press: New York, NY (1986).

47. P.M. Herold, J.E. Kinsella; Am. J. Clin. Nutr. 43, 566 (1986).

48. E. Kovats; Helv. Chim. Acta 41, 1915 (1958).

49. L.S. Ettre; Chromatographia 6, 489 (1987).

50. M. Özcimder, W.E. Hammers; J. Chromatogr. 187, 307 (1980).

51. J.S. Yoo, V.L. McGuffin; J. Chromatogr. 627, 87 (1992).

52. R.J. Laub, J. H. Purnell; J. Chromatogr. 112, 71 (1975).

53. R.J. Laub; J. Liq. Chromatogr. 7, 647 (1984).

54. E.M. Kosower; J. Am. Chem. Soc. 80, 3253 (1958).

55. D.C. Dong, M.A. Winnik; Can. J. Chem. 62, 2560 (1984).

56. J.W. Carr, J.M. Harris; Anal. Chem. 59, 2546 (1987).

57. J. Stahlberg, M. Almgren, J. Alsins; Anal. Chem. 60, 2487 (1988).

58. S.H. Chen, V.L. McGuffin; Appl. Spectrosc., manuscript in preparation.

59. M.E. Sigman, S.M. Lindley, J.E. Leffler; J. Am. Chem. Soc. 107, 1471 (1985).

60. C.R. Yonker, S.L. Frye, D.R. Kalkwart, R.D. Smith; J. Phys. Chem. 90, 3022 (1986).

61. C.R. Yonker, R.D. Smith; J. Phys. Chem. 92, 235 (1988).

62. K.W. Street, W.W. Acree; Analyst 111, 1197 (1986).

63. K.W. Street, W.W. Acree; Analyst 113, 1465 (1988).

64. J.F. Brennecke, C.A. Eckert; ACS Symp. Ser. 406, 14 (1989).

65. J.F. Brennecke, D.L. Tomasko, J. Peshkin, C.A. Eckert; Ind. Eng. Chem. Res. 29, $1682(1990)$.

66. L.M. Stephen, B.D. Olafs sn, W.A.Goddard; J. Phys. Chem. 94, 8897 (1990).

67. C. Reichardt; Solvents and Solvent Effects in Organic Chemistry; $\mathrm{VCH}$ Publishers: New York, NY (1988); p. 10-11.

68. S.H. Chen, C.E. Evans, V.L. McGuffin; Anal. Chim. Acta 246, 65 (1991).

69. F.K. Ogasawara, Y. Wang, V.L. McGuffin; Appl. Spectrosc., manuscript in preparation. 


\section{PUBLICATIONS AND REPORTS OF THE RESEARCH PROJECT}

1. C.E. Evans, V.L. McGuffin; "Retention and Dispersion Processes along a Liquid Chromatographic Microcolumn"; in Proc. Int. Symp. Capillary Chromatogr. 11, 802-814 (1990); P. Sandra, G. Redant, Eds.; Huethig: Heidelberg, F.R.G.

2. V.L. McGuffin, C.E. Evans; "The Influence of Pressure on Solute Retention in Liquid Chromatography"; in Proc. Int. Symp. Capillary Chromatogr. 12, 90-99 (1991); P. Sandra, Ed.; Huethig: Heidelberg, F.R.G.

3. C.E. Evans, V.L. McGuffin; "Direct Examination of the Injection Process in Liquid Chromatographic Separations"; Anal. Chem. 63, 1393-1402 (1991).

4. V.L. McGuffin, C.E. Evans; "Influence of Pressure on Solute Retention in Liquid Chromatography"; J. Microcol. Sep. 3, 513-520 (1991).

5. S.H. Chen, C.E. Evans, V.L. McGuffin; "Selective Fluorescence Quenching of Polynuclear Aromatic Hydrocarbons in Microcolumn Liquid Chromatography"; Anal. Chim. Acta 246, 65-74 (1991).

6. V.L. McGuffin, C.E. Evans, S.H. Chen; "Direct Examination of Separation Processes in Liquid Chromatography by Laser-Induced Fluorescence"; in Proc. Int. Symp. Capillary Chromatogr. 14, 417-426 (1992); P. Sandra and M.L. Lee, Eds.; Huethig: Heidelberg, F.R.G.

7. J.S. Yoo, V.L. McGuffin; "Determination of Fatty Acids in Fish Oil Dietary Supplements by Capillary Liquid Chromatography with Laser-Induced Fluorescence Detection"; J. Chromatogr. 627, 87-96 (i99').

8. V.L. McGuffin, C.E. Evans, S.H. Chen; "Direct Examination of Separation Processes in Liquid Chromatography: Effect of Temperature and Pressure on Solute Retention"; J. Microcol. Sep., in press (1992).

9. C.E. Evans, S.H. Chen, V.L. McGuffin; "Theoretical and Experimental Studies of the Effect of Pressure on Solute Retention in Liquid Chromatography"; Anal. Chem., submitted for publication.

10. C.E. Evans, J.S. Yoo, V.L. McGuffin; "Direct Examination of the Elution Process in Liquid Chromatographic Separations"; Anal. Chem., manuscript in preparation.

11. S.H. Chen, V.L. McGuffin; "Temperature Effect on Pyrene as a Polarity Probe for Supercritical Fluid and Liquid Solutions"; Appl. Spectrosc., manuscript in preparation.

12. F.K. Ogasawara, Y. Wang, V.L. McGuffin; "Evaluation of 1,2,4Trimethoxybenzene and Nitrobenzene as Selective Fluorescence Quenching Agents for Polynuclear Aromatic Hydrocarbons in Liquid Chromatography", Anal. Chem., manuscript in preparation.

13. F.K. Ogasawara, Y. Wang, V.L. McGuffin; "Examination of FluorophoreQuencher Interactions by Semiempirical Quantum Mechanics and Molecular Dynamics Methods"; Appl. Spectrosc., manuscript in preparation. 


\section{PERSONNEL OF THE RESEA.RCH PROJECT}

Christine E. Evans, graduate student (1985-1991), Ph.D. thesis "Fundamental Studies of Capillary Columns in Liquid Chromatography"

Jon H. Wahl, graduate student (1985-1991), Ph.D. thesis "Solvent Modulation in Liquid Chromatography: An Alternative to Premixed Mobile Phases"

Jong Shin Yoo, graduate student (1986-1G92), Ph.D. thesis "Temperature-Programmed Microcolumn Liquid Chromatography/Mass Spectrometry"

Shu-Hui Chen, graduate student (1987 to present)

Yiwen Wang, graduate student (1989-1991), M.S. thesis "Application of Computer Simulation for Investigation of Fluorescence Quenching Mechanisms"

Daniel H. Hopkins, graduate student (1989 to present)

Chomin Lee, graduate student (1991 to present)

Dr. Faye K. Ogasawara, postdoctoral research associate (1991 to present) 

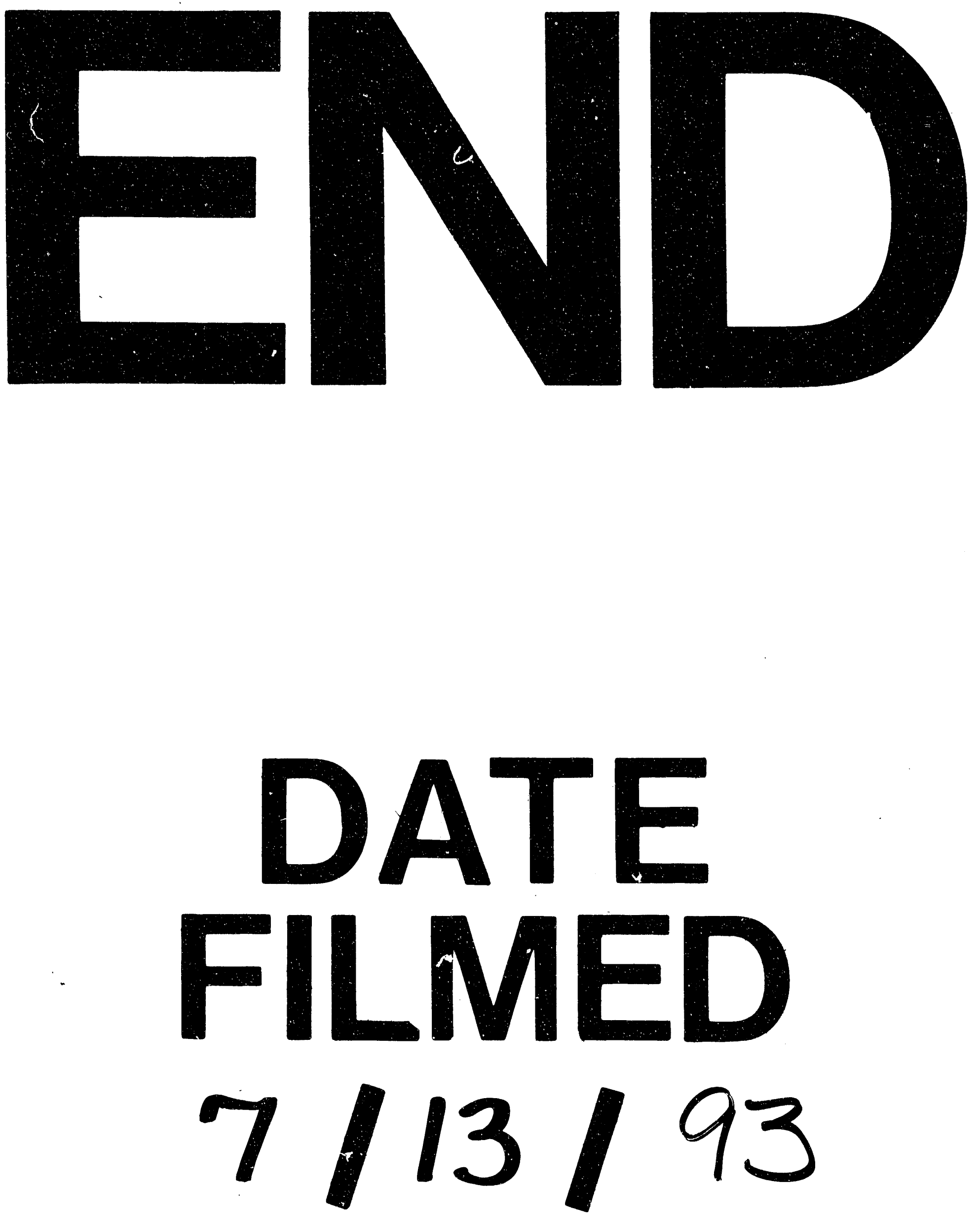

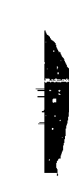


